\title{
Health and social welfare professionals' self-rated competence and feedback following a simulation-based coaching intervention in small and medium-sized enterprises
}

\author{
Mari Helena Salminen-Tuomaala*1, Elina Kangasluoma ${ }^{1}$, Kirsi Paavola ${ }^{1}$, Sami Perälä ${ }^{1}$, Sirke Uitto ${ }^{2}$ \\ ${ }^{1}$ Seinäjoki University of Applied Sciences, School of Health Care and Social Work, Finland \\ ${ }^{2}$ Seinäjoki Vocational Centre Sedu, Finland
}

Received: June 29, 2019

DOI: $10.5430 / \mathrm{cns} . v 7 \mathrm{n} 4 \mathrm{p} 30$
Accepted: September 20, 2019 Online Published: September 27, 2018

URL: https://doi.org/10.5430/cns.v7n4p30

\begin{abstract}
Objective: To examine how health and social welfare professionals in small and medium-sized companies (SMEs) rated their theoretical, practical, and interaction competencies following simulation-based coaching, and to collect feedback for the coaching intervention.

Methods: This quantitative survey is part of a wider research and development project conducted in Finland in the years 20172019 with assistance from the European Social Fund and carried out in collaboration between two educational institutions. Respondents were 107 nurses and other health and social care professionals in 20 SMEs. Data collection took place using an online questionnaire in May 2019. The data were analyzed using IBM SPSS for Windows 25.

Results: The great majority of the participants were satisfied with the coaching intervention. Respondents rated their theoretical, practical, and interaction competencies as good. They also felt confident about their skills in learning, problem-solving, and action-based learning. Among the most salient learning needs were the use of digital tools, social media, and electronic learning environments, and the need to practice remote counseling.

Conclusions: The results indicate a need to provide continuing education on information and communication technology for health and social welfare professionals in small and medium-sized companies.
\end{abstract}

Key Words: Theoretical competence, Practical competence, Simulation-based coaching, Staff, Small and medium-sized enterprise

\section{INTRODUCTION}

Research has shown that continuous professional development is important and that learning in the work environment is useful from the perspective of individuals and organizations alike. ${ }^{[1,2]}$ It has been proposed that not only concrete, situation and workplace-specific, but also adaptable, trans- ferable learning can take place in workplaces, either through everyday activities or through organized workplace learning. Transferable and conceptual learning is thus not only confined to educational institutions. Workplace learning depends on participation and interaction, not only with the social but also with the physical environment, and it is always a result of

\footnotetext{
*Correspondence: Mari Helena Salminen-Tuomaala; Email: Mari.Salminen-Tuomaala@seamk.fi; Address: Seinäjoki University of Applied Sciences, School of Health Care and Social Work, Finland.
} 
individual engagement and construction of knowledge. ${ }^{[3]} \mathrm{Im}-$ portant contributions to the organizational learning approach include the work of Argyris and Schön ${ }^{[4]}$ and Engeström's expansive learning approach within the framework of activity theory. ${ }^{[5]}$

Professional competence can be seen as depending on a combination of formal, practical, metacognitive, and reflective knowledge. Practical knowledge is born out of experience. It is associated with the culture where it is born, and it is often tacit knowledge, which helps the employee assess situations and solve problems. Formal or theoretical knowledge is explicit, and it is required to justify and give reasons for actions and solutions. Metacognitive and reflective knowledge are self-regulatory; they refer to self-evaluation, awareness, and responsibility for one's actions. In experienced professionals, knowledge, skills, and self-regulation become integrated and expressed in flexible action. ${ }^{[6]}$

In the world of work, effective educational interventions are based on an assessment of learning needs, tailored to the needs of the organization and, if possible, carried out in the work context, in the organization's premises. ${ }^{[2,7]}$ It has been suggested that besides attending to specific learning needs, the educators should look into the training culture, that is the meanings and values attributed to training in the organization. The individual, group, and organizational aspects of training culture may be different, and a clash may exist between employee and management perspectives. An instrument (Training Culture Scale) has been recently developed for the measurement of training culture. ${ }^{[8]}$

In social and health care industries, action-based learning methods, for example simulation, have been recommended as effective means to practice teamwork and communication, as well as various client or patient situations. ${ }^{[3,9,10]}$ Simulation by definition imitates reality in a nearly authentic context. Although the learning objectives may be based on competence level assessments and carefully defined and delineated learning needs, the learning experience is more holistic and immersive. ${ }^{[11]}$ In simulation-based training, learning takes place through an alternation of experiencing, doing, feeling, and reflection, ${ }^{[12]}$ the last activity being important for the development of ethical competence. ${ }^{[13]}$ Besides teamwork skills, simulation has been found to facilitate the creation of shared mental models ${ }^{[14]}$ and to allow learning from mistakes without risk to clients. ${ }^{[15-18]}$ According to research, simulation can change existing behavioral habits and help the participant detect the change. Although simulation laboratories in educational institutions have been proved very useful for skills development, practicing in a genuine clinical environment can also be very much recommended. ${ }^{[18,19]}$
In Europe, the European Union, national governments, and other authorities have a role in steering professional development and workplace education. As recommended by the European Commission, foresight work, or future-oriented thinking, is necessary to anticipate and prepare for changing competence requirements not only nationally, but also regionally. ${ }^{[20]}$ In Finland, where this study was conducted, a national survey on educational needs lists current challenges to and healthcare education: The population is aging, but also becoming increasingly international and multicultural, with a wider range of service needs. New practices and job descriptions evolve, and multidisciplinary and multi-professional collaboration and an extensive knowledge base are necessary to serve clients with multiple, complex problems. ${ }^{[21]}$

The responsible Ministry in Finland has compiled some key concepts and measures in response to the changes and new demands faced by workplaces. According to the Ministry, competence management - or management of learning and development- should involve workplace training based on foresight work and assessment of learning needs; orientation of new employees; mentoring, and sharing of skills and knowledge. Successful competence management, which very much depends on management practices, can increase wellbeing at work ${ }^{[22]}$ and in an ideal case, lead to the creation of a shared vision, applicable to practice. ${ }^{[23]}$ Learning together as a working community can increase commitment to the work and profession. ${ }^{[24]}$ A creative approach is required at workplaces to foster participation, alternative ways of thinking and new practices. ${ }^{[25]}$

Regarding social and health care industries specifically, the Ministry guidelines currently stress the importance of developing multi-professional collaboration and teamwork, as well as client-centered counseling, case management, and coordination of services. Further important areas include research and development; evidence-based practice, digitalization and technology; cost-effectiveness, and sustainable development. The Ministry recommends that new learning environments and structures for competence development should be planned and implemented. Special attention should be paid to increasing employees' awareness of the potential of digital solutions. Digital tools and technology can renew practices and client service and help clients make informed health choices. ${ }^{[26]}$

The need to increase information technology and digital services has proved to be a challenge to health and social care systems, and technology use and skills vary a great deal from one unit to another. A generation gap seems to exist, with an increasing demand for digital services from clients, who have been using information technology since their child- 
hood. Digital services are time-saving and cost-effective, but developing them for health and social care industries is not a simple task. Multiprofessional teams and interdisciplinary competence are required; besides technological solutions, the developers need to be cognizant of the knowledge, legislation, and practices that are specific for health and social services. Although the use of applications or remote services is not necessarily complicated, the entire process of developing and bringing them into practice is not always straightforward. Once the development process is over, potential users may still need support, remote counseling, and simulation coaching to be able to use the services effectively. ${ }^{[27]}$

\subsection{Study background}

This paper presents a sub-study of a wider research and development undertaking conducted in Finland from August 2017 until December 2019. The overall project, whose purpose was to offer tailor-made simulation-based coaching for social and health care staff in the region's small and mediumsized enterprises, was carried out in collaboration between a vocational education institution and a university of applied sciences, with assistance from the European Social Fund. The project started with visits to the enterprises, 20 regional companies representing social and health care industries, and with surveys on participants' self-reporting learning needs and competency levels, conducted in 2017. ${ }^{[2,10,28]}$ Based on this work, a series of simulation-based coaching interventions was planned for the participants and pre-tested with mature nurse nursing degree students, who had a vocational qualification (e.g. practical nurse). This paper presents the results of a quantitative survey conducted after the simulation-based coaching intervention.

\subsection{Research problems}

The study seeks to examine how health and social welfare professionals in small and medium-sized enterprises (SMEs) estimated their theoretical, practical and interaction competencies following simulation-based coaching, and to collect feedback for the coaching intervention. The aim is to answer the following questions:

1. How do health and social welfare professionals in SMEs estimate their theoretical, practical, and interaction competencies following a simulation-based coaching intervention?

2. How do the professionals evaluate the simulation coaching intervention?

\section{RESEARCH METHODS}

\subsection{Sample and coaching intervention}

The 107 respondents, most of whom had a nursing background, represented 20 SMEs engaged in child welfare, elderly care, mental health, and disability services. The 20 enterprises were originally recruited through telephone calls from the project manager, after failing to attract participants through a notice in a regional newspaper. One third of the 60 enterprises contacted agreed to take part in the project. Following surveys on self-assessed learning needs and competency levels, ${ }^{[28]}$ the participants took part in 4-8hour simulation-based coaching interventions conducted by two expert lecturers in the enterprises' facilities. In total, the simulation coaching interventions involved 120 sessions. The lecturers varied, as they were selected based on the area of expertise required in the various enterprises.

The sessions always started with discussion on the simulation-based coaching method, with attention being paid to the creation of an ethical, safe learning atmosphere. Pairs of learners, decided by lot, received their respective instructions for the scenario, including learning aims, the context of the scenario and a short description of the situation at the onset. An example of a scenario has been attached (see Appendix 1). Each pair of learners used 10-15 minutes to prepare for the scenario together, and 10 minutes to carry out action. One of the lecturers played the part of the patient or family member, and the other lecturer assumed responsibility for supervising the overall learning situation. The other participants were assigned observation tasks focusing on relevant aspects of the situation, for example interaction, teamwork, empathy skills, concrete intervention skills or logical progress of the situation. The session always ended with a 45-minute discussion, chaired by the two lecturers, who encouraged partipants to engage in open feedback and reflection.

Among the topics, selected for these sessions based on participant wishes and learning needs assessments, were the management of acute situations; client and patient safety; quality of end-of-life care; dialogue and emotional intelligence; interaction and teamwork; remote counseling and digital skills; encountering children and their families; encountering clients with mental health problems; challenges in pharmaceutical care; and development of clinical nursing or caring interventions.

\subsection{Data collection and analysis}

Data collection for this paper took place in the first three weeks of May in 2019. The same respondents who had rated their theoretical, practical, and interaction competencies in 2017, before the simulation coaching, were invited to complete another online survey using a tool called Webropol. The questionnaire, based on a systematic literature review was, for the most part, the same as the one used in the collection of data in 2017, but eight questions dealing with the simula- 
tion coaching were added to the original items. Starting with eight questions about respondents' age, sex, and educational and occupational background, the questionnaire consisted of 50 quantitative Likert type questions. The purpose of the Likert type items was to gain the respondents' general evaluation of the simulation coaching intervention and to look into their various competencies after the intervention. The options on the 1-5 scale were very good; fairly good; neutral (worded "neither good nor poor"); fairly poor; and very poor. A translated copy of the questionnaire has been attached (see Appendix 2).

IBM SPSS Statistics for Windows 25 was used in data analysis. The respondents were organized into categories for further analysis and comparison. There were four age categories: under $30,30-39,40-49$, and 50 or older. The five categories by education involved primary or secondary level general education; upper secondary level general education; vocational qualification; college, and university of applied sciences. There were also five categories for the various qualifications held by respondents: Practical Nurse (Enrolled Nurse); Nurse; Bachelor of Social Services; Youth and Leisure Instructor; and other.

Respondents' self-rated competencies are presented using measures of central tendency. Only the highest percentages are included in the text; in most cases, shares under $10 \%$ have been left out, partly to improve readability. The statistical significance level was set at $p<.05$, and levels $<.01$ were considered very significant. ${ }^{[29]}$ The distribution was skewed, so the Mann-Whitney $U$ test and Kruskal-Wallis test were used to search for differences between participant categories.

\subsection{Research ethics, reliability and validity}

In alignment with the ethical guidelines of the National Board on Research Integrity in Finland, participants were recruited through personal e-mails, which provided information about the study and emphasized the voluntary nature of the study. ${ }^{[30,31]}$ The questionnaire was accessible through a link in the e-mail. All responses were anonymous and not linked to the e-mail addresses. The data was stored in a database protected by a password, ${ }^{[32]}$ accessible only to the investigator, who analyzed the data following the generally accepted research integrity guidelines. ${ }^{[30]}$

Careful consideration was paid to the formation and testing of the questionnaire to ensure the reliability of the study. The questionnaire was based on a systematic literature review, on an earlier competency assessment conducted in the enterprises and on the project team's common opinion reached through discussion and reflection. Most items were the same as in the earlier study, ${ }^{[10]}$ during which special attention had been paid to the formulation of the Likert-type items to faciliPublished by Sciedu Press tate analysis and clear reporting. As suggested in research, ${ }^{[33]}$ an expert panel was consulted to support the operationalization process. The content validity of the instrument was discussed among the project team and steering group, where all members had an opportunity to suggest changes at two points of time; at the beginning of the project, and just before conducting the survey. The questionnaire was pre-tested by ten persons (two from regional enterprises and eight from the project steering group) to examine if the questions suggested were required, comprehensibly formulated and in a logical order, and if the response options were meaningful and mutually exclusive. On advice from the expert panel, eight items were added to the existing questionnaire. As recommended for electronic survey tools, ${ }^{[34]}$ two members of the project group tested the Webropol tool before sending the link to the target group.

The response rate was high $(86 \%)$, which enhances the reliability of the study. ${ }^{[35]}$ It can be argued that the sample is well representative of the population size $(200,000)$ in the region, in a country with a population of 5.5 million. Study reliability is, however, decreased by the fact of having a single investigator conduct the analysis. External validity may be affected by the great majority of the respondents being women. On the other hand, the large majority of the employees in social and health care industries are female. The response rate might have been affected by the fact that not all employees had a computer for their personal use. ${ }^{[34]}$ Still, all enterprises provided their employees access to one or several computers.

\section{Results}

\subsection{Demographic data}

The response rate was $86 \%(\mathrm{n}=107)$. The great majority of the participants, $88 \%(n=93)$, were women, but one person did not respond to this item. The age range was 19-62 years, with the share of those between 40 and 62 dominating the sample.

As shown in Table 1, most respondents in this study had a nursing background and a post-secondary vocational or professional qualification. There were, however, four persons with a secondary level general education, four with an upper secondary level general education, and one respondent, who did not provide an answer. The greatest single occupational groups were Practical Nurses and Nurses. The category "other" consisted of 12 individuals, each of whom had a different educational background: Teacher; Bachelors' degree in elderly care/physiotherapy/occupational therapy/community education/business administration; Care Assistant; Home Care Assistant; Ward Domestic; Restaurant Manager; Caretaker; and Textile Artisan. 
Table 1. Demographic data on the participants

\begin{tabular}{|c|c|c|}
\hline Background Variable & $\mathbf{n}$ & $\%$ \\
\hline \multicolumn{3}{|l|}{ Age } \\
\hline Under 40 years & 37 & 35 \\
\hline $40-49$ years & 30 & 28 \\
\hline 50 years or older & 30 & 28 \\
\hline \multicolumn{3}{|l|}{ Sex } \\
\hline Woman & 93 & 88 \\
\hline Man & 13 & 12 \\
\hline \multicolumn{3}{|l|}{ Educational Background } \\
\hline Secondary or upper secondary-level general education & 8 & 11 \\
\hline Vocational qualification & 37 & 40 \\
\hline Professional qualification & 19 & 18 \\
\hline University of Applied Sciences & 33 & 31 \\
\hline \multicolumn{3}{|l|}{ Diploma or Degree Title } \\
\hline Nurse & 20 & 19 \\
\hline Bachelor of Social Services & 15 & 14 \\
\hline Practical Nurse & 52 & 49 \\
\hline Youth and Leisure Instructor & 5 & 5 \\
\hline Other & 12 & 11 \\
\hline \multicolumn{3}{|l|}{ Scope of Responsibility } \\
\hline Management/leadership & 20 & 19 \\
\hline Guidance and counseling & 54 & 58 \\
\hline Promoting clients' ability to function & 69 & 64 \\
\hline Assisting clients with basic activities & 72 & 67 \\
\hline Supporting clients' development and growth & 36 & 34 \\
\hline
\end{tabular}

The respondents worked in child welfare, elderly care, mental health, and disability services. In practice, the participants' scope of responsibility involved one or more the following areas: promoting clients' ability to function; assisting clients with basic activities; guidance and counseling; supporting development and growth; and management/leadership. Other duties specified by $5 \%$ of the respondents involved driving, team leading, financial management, animal care, facilities maintenance, and coordinating everyday practical activities.

\subsection{General feedback for simulation-based coaching}

Simulation-based training was a new experience for most participants - only $41 \%$ had some previous experience of simulation - but the great majority were satisfied with the coaching intervention. Almost half (48\%) of the participants felt that their learning needs had been very well attended to, and $41 \%$ said that their learning needs had been met fairly well. The feedback was similar for the development of professional competence. Again, the majority of the participants found that simulation coaching had promoted their professional competence (very well: $43 \%$; fairly well: $39 \%$ ). Also, the respondents agreed on the high level of usefulness and adaptability of the contents learned. They had been able to make use of the new contents fairly well $(50 \%)$ or very well (33\%). Negative ratings were few (fairly poorly: $7 \%$; very poorly: $6 \%$ ).

Finally, when asked about their possibilities to suggest learning contents for simulation coaching, the greatest group of respondents (38\%) gave a neutral response. The share of positive opinions was higher than that of negative responses; very good: $17 \%$; and fairly good: $19 \%$, compared to fairly poor: $10 \%$, and very poor: $10 \%$. Six participants did not respond to this item.

\subsection{Self-rated theoretical knowledge}

\subsubsection{Knowledge of simulation learning}

With most professionals in this study having no previous experience of simulation-based learning, a moderate share of all participants felt that their knowledge of simulation learning was fairly good (44\%) or very good (7\%). More than one fifth (22\%) chose the neutral option, $18 \%$ the option 
fairly poor, and $8 \%$ the option very poor. Nurses may have had higher self-ratings than Bachelors of Social Sciences; the Kruskal-Wallis test revealed a statistically nearly significant difference between the two groups $(p=.051)$.

\subsubsection{Knowledge needed in work with clients}

Table 2 shows that the respondents were asked to rate their theoretical knowledge of various areas of client work. First, it was discovered that following the simulation-based coaching intervention, most respondents had fairly good $(62 \%)$ or very good $(28 \%)$ self-rated theoretical knowledge of the iden- tification of needs for nursing or care. Second, the respondents especially appreciated their theoretical understanding of advising clients on physical function; $67 \%$ estimated their knowledge as very good and $21 \%$ as fairly good. The results were slightly lower, but still encouraging, for knowledge of supporting clients' psychosocial function: fairly good 68\%; very good $13 \%$; and neither good nor poor $14 \%$. Two statistically significant observations were made: Nurses ( $p=$ $.003)$ and Practical Nurses $(p=.002)$ had better self-rated knowledge of physical function than Bachelors of Social Sciences.

Table 2. Self-rated practical competence

\begin{tabular}{|c|c|c|c|c|c|}
\hline & Very good & Fairly good & Neutral & Fairly poor & Very poor \\
\hline Knowledge of the identification of needs for nursing or care & $62 \%$ & $28 \%$ & $10 \%$ & & \\
\hline Understanding of advising clients on physical function & $67 \%$ & $21 \%$ & $12 \%$ & & \\
\hline Knowledge of supporting clients' psychosocial function & $68 \%$ & $13 \%$ & $14 \%$ & $5 \%$ & \\
\hline Knowledge of chronic illness & $14 \%$ & $56 \%$ & $20 \%$ & $10 \%$ & \\
\hline Knowledge of acute illness & $14 \%$ & $51 \%$ & $33 \%$ & $2 \%$ & \\
\hline Knowledge of action to be taken in acute situations & $13 \%$ & $34 \%$ & $25 \%$ & $14 \%$ & $14 \%$ \\
\hline Knowledge of encountering violence & $50 \%$ & & $33 \%$ & $17 \%$ & \\
\hline Knowledge of severe disability & $2 \%$ & $20 \%$ & $51 \%$ & $16 \%$ & $11 \%$ \\
\hline
\end{tabular}

Third, it seems based on the results that the respondents were somewhat less confident about their knowledge when counseling clients on chronic and, especially, on acute illness. More than half of the respondents opted for "fairly good" fairly good knowledge of chronic illness (56\%), fairly good knowledge of acute illness (51\%), and fairly good understanding of the steps to be taken in acute situations $(62 \%)$. Only $14 \%$ reported very good knowledge of the chronic and acute illness, and over one third were unable to determine if their knowledge was good or poor. Similarly, only $13 \%$ felt that they had very good knowledge of action to be taken in acute situations. Again, Nurses and Practical Nurses had significantly higher ratings than Bachelors of Social Services. The differences were $(p=.000)$ and $(p=.004)$, respectively. The Kruskal-Wallis test also revealed a statistically significant difference between Practical Nurses and several other occupational groups (Physiotherapist and Bachelors of elderly care/community education/ occupational therapy) regarding knowledge of acute illness ( $p=.009$ ) and a nearly significant difference between Nurses and the same occupational groups $(p=.028)$.

Fourth, the ratings went further down when respondents were inquired about their knowledge of encountering violence and, especially, about their knowledge of severe disability. Half of the respondents found that they knew fairly well how to deal with violent clients, but $33 \%$ chose "neither good nor poor knowledge". More than half of the participants (51\%) gave a neutral response, neither good nor poor, to the item on severe disability. One fourth rated their knowledge of severe disability as fairly good, and $16 \%$ as fairly poor.

The Mann-Whitney $U$ Test did not reveal any statistically significant differences between women and men in any area of theoretical knowledge. The Kruskal-Wallis test showed that respondents in the age group 40-49 rated their knowledge of severe disability as higher than the 30-39-year-olds. The difference was statistically significant $(p=.026)$.

\subsection{Self-rated practical competence}

Besides theoretical knowledge, the respondents were asked to evaluate their general practical competence and a wide variety of skills required in their work (see Table 3). Almost half of the respondents $(48 \%)$ rated their practical competence as fairly good, $22 \%$ as very good, and $20 \%$ chose the neutral option. The most important results have been drawn together as follows.

\subsubsection{Selection of appropriate interventions}

The participants were asked to rate their skills in selecting appropriate interventions for their clients. The responses were divided between fairly good (48\%), very good (22\%) and neither $(20 \%)$. The results were similar, although slightly lower, for selecting interventions in acute situations: fairly 
good skills (53\%), very good skills (14\%) and neither (25\%), and for finding means to encounter aggressive or defiant behavior: fairly good $(56 \%)$, very good $(6 \%)$ and neither (31\%). The Kruskal-Wallis test indicated that Nurses and Practical Nurses rated their skills in acute situations higher than Physiotherapists, Occupational therapists, and Bachelors of elderly care or community education. The differences were nearly significant $(p=.031$ and $p=.041)$.

\subsubsection{Supporting clients}

A clear majority of the professionals in this study were fairly satisfied with their skills in supporting clients in conflict situations $(68 \%)$ and in supporting family members $(66 \%)$. The ratings were higher for the skill to support family members: (very good 14\%; 15\% Neither good nor poor), compared to the skill to support clients facing conflict situations (very good 4\%; neither good nor poor 23\%).

Table 3. Self-rated practical competence

\begin{tabular}{|c|c|c|c|c|c|}
\hline & Very good & Fairly good & Neutral & Fairly poor & Very poor \\
\hline General practical competence for the work & $22 \%$ & $48 \%$ & $20 \%$ & $10 \%$ & \\
\hline Skills in selecting appropriate interventions & $22 \%$ & $48 \%$ & $20 \%$ & $5 \%$ & $5 \%$ \\
\hline Selecting interventions in acute situations & $14 \%$ & $53 \%$ & $25 \%$ & $8 \%$ & \\
\hline Finding means to encounter aggressive or defiant behavior & $6 \%$ & $56 \%$ & $31 \%$ & $7 \%$ & \\
\hline Supporting clients in conflict situations & $4 \%$ & $68 \%$ & $23 \%$ & $5 \%$ & \\
\hline Supporting family members & $14 \%$ & $66 \%$ & $15 \%$ & $5 \%$ & \\
\hline Safety skills & $26 \%$ & $60 \%$ & $14 \%$ & $20 \%$ & \\
\hline Development of client safety skills & $13 \%$ & $24 \%$ & $43 \%$ & $20 \%$ & \\
\hline Development of occupational safety skills & $13 \%$ & $27 \%$ & $42 \%$ & $18 \%$ & \\
\hline Use of various applications & $15 \%$ & $32 \%$ & $33 \%$ & $16 \%$ & $4 \%$ \\
\hline Technological communication skills & & $10 \%$ & $40 \%$ & $20 \%$ & $30 \%$ \\
\hline Social media skills & $10 \%$ & $39 \%$ & $20 \%$ & $20 \%$ & $11 \%$ \\
\hline Remote counseling skills & & $17 \%$ & $42 \%$ & $33 \%$ & $8 \%$ \\
\hline Development of information technology skills & $2 \%$ & $15 \%$ & $52 \%$ & $17 \%$ & $14 \%$ \\
\hline Day-to-day organizing skills & $27 \%$ & $62 \%$ & $11 \%$ & & \\
\hline Decision-making skills & $15 \%$ & $63 \%$ & $20 \%$ & $2 \%$ & \\
\hline Mentoring skills & $15 \%$ & $55 \%$ & $20 \%$ & $10 \%$ & \\
\hline Encouraging colleagues & $20 \%$ & $59 \%$ & 15 & $6 \%$ & \\
\hline Conducting discussions with staff members & & $21 \%$ & $47 \%$ & $32 \%$ & \\
\hline Entrepreneurship skills & $5 \%$ & $26 \%$ & $40 \%$ & $19 \%$ & $10 \%$ \\
\hline Marketing skills & $5 \%$ & $36 \%$ & $49 \%$ & $15 \%$ & \\
\hline Improving the competitiveness of the enterprise & & $45 \%$ & $36 \%$ & $17 \%$ & $2 \%$ \\
\hline Improving the attractiveness of the enterprise for clients & $13 \%$ & $47 \%$ & $36 \%$ & $4 \%$ & \\
\hline Improving the attractiveness of the enterprise for new employees & $14 \%$ & $44 \%$ & $34 \%$ & $8 \%$ & \\
\hline Keeping up with changes in society & $10 \%$ & $38 \%$ & $43 \%$ & $8 \%$ & \\
\hline Identification of future challenges & $8 \%$ & $44 \%$ & $42 \%$ & $6 \%$ & \\
\hline Continuous learning skills & $25 \%$ & $55 \%$ & $10 \%$ & $10 \%$ & \\
\hline Skills in action-based learning & $26 \%$ & $58 \%$ & $16 \%$ & & \\
\hline Creative problem-solving skills & $22 \%$ & $56 \%$ & $20 \%$ & $2 \%$ & \\
\hline
\end{tabular}

\subsubsection{Attending to safety}

The results were good for skills in attending to client safety. Most respondents were confident that they were fairly well $(60 \%)$ or very well $(26 \%)$ equipped to ensure the safety of their clients. A moderate number of respondents also felt that their client safety skills had developed during the sim- ulation coaching (very much, 13\%; fairly much 24\%). The greatest group, $43 \%$, however, did not report any change. Similar results were obtained for self-rated development of occupational safety skills: very much development, $13 \%$; fairly much development, $27 \%$, and neither much nor little development, $42 \%$. 


\subsubsection{Keeping up with the technological development}

There was more variation in the respondents' self-rated skills in information and communication technology, compared to the other aspects of client work discussed above. For example, one-third of $33 \%$ of the professionals in this study said that their skills in using various applications were neither good nor poor and $32 \%$ chose the option "fairly good skills", but $16 \%$ estimated their skills as fairly poor and $15 \%$ as very good. The results were very similar for technological communication skills, use of the Moodle learning environment, and use of digital tools, with the largest group of the participants, 36\%-40\%, choosing the response "neither good nor poor skills" to these items. When asked about their skills in using social media, however, "fairly good skills" became the most frequently chosen option (39\%) among the respondents. The ratings were by far lowest for remote counseling skills: neutral $42 \%$; fairly poor $33 \%$; fairly good $17 \%$. The ratings are not representative of the whole sample, because $56 \%$ (n $=60$ ) of the respondents did not participate in the training sessions on remote counseling and case management.

Moreover, some variation was detected between younger and older age groups. The under 30-year-old respondents felt better equipped to use various ICT applications $(p=.019)$, to engage in technological communication $(p=.000)$ and to use social media $(p=.001)$ than the respondents who were past 50. Also, the age group 40-49 felt more confident about their technological communication skills $(p=.005)$ than the age group 50 and older.

Having taken part in the simulation coaching, more than half of the respondents (52\%) estimated their development in information technology in general as neither good nor poor. The other responses were centered around the midpoint: fairly much development $15 \%$, and fairly little development, $17 \%$. It also seems that there was little development in the respondents' remote counseling skills: did not participate in the training sessions $56 \%$; fairly much development $13 \%$; fairly little development, $13 \%$ and very little development, $11 \%$.

\subsubsection{Leadership, management, and entrepreneurship skills}

Part of the respondents in this study (19\%) had a double role; besides practical care work, they were also leaders and entrepreneurs in the companies. Still, all respondents were asked to respond to the items here gathered under the title leadership, management, and entrepreneurship. These skills can be considered important for any employee, at least from a self-management perspective.

The respondents reported fairly good (62\%) and very good $(27 \%)$ skills in organizing day-to-day activities. The results were positive for decision-making skills as well: fairly good $(63 \%)$, neutral $(20 \%)$, very good $(15 \%)$. Over half of the respondents also felt confident that they had fairly good skills in mentoring (55\%) and in encouraging colleagues to deal with challenging tasks $(59 \%)$.

Remembering that only one-fifth of the respondents were involved in management, it is not surprising that the greatest group, $47 \%$ chose the neutral option "neither good nor poor skills" for conducting discussions with staff members. Still, $32 \%$ reported fairly good skills. It was also to be expected that respondents involved in management reported significantly better skills in conducting discussions with staff members than other respondents $(p=.000)$. As regards mentoring skills, the Mann-Whitney $U$ Test showed a nearly significant difference $(p=.029)$ between managers and other occupational groups, with those involved in management scoring higher.

There was relatively much variation in respondents' selfrated entrepreneurship skills: neutral $40 \%$, fairly good $26 \%$, and fairly poor skills, $19 \%$. Those involved in management again reported better skills compared to other respondents $(p=.000)$. All respondents were somewhat more confident regarding their skills in marketing (neutral 49\%, fairly good $36 \%$ ), in improving the competitiveness of the enterprise (neutral 36\%, fairly good $45 \%$ ) and, especially, in improving the attractiveness of the enterprise in the eyes of clients (fairly good $47 \%$, neutral $31 \%$, very good $13 \%$ ) or new employees (fairly good $44 \%$, neutral $34 \%$, very good $14 \%$ ).

When asked about their skills in keeping up with changes in society, which can be seen as integral to both entrepreneurship and to the development of client work, the greatest group of the professionals in this study (43\%) felt unable to say whether they possessed limited or good skills. However, 38\% reported fairly good and $10 \%$ very good skills. The results were similar for identification of future challenges: (fairly good $44 \%$, neutral $42 \%$, very good $8 \%$ ).

\subsubsection{Learning and problem-solving skills}

The results further revealed the respondents' strong trust in their continuous learning skills. The great majority of the respondents estimated their skills to be fairly good $(55 \%)$ or very good $(25 \%)$. The results were equally encouraging for action-based learning: fairly good (58\%), very good (26\%) and creative problem-solving: fairly good $(56 \%)$ or very good $(22 \%)$. Most respondents also felt assured of being prepared for further development of their practical competence in general (fairly or very good skills; $56 \%$ and $31 \%$ respectively).

There was some indication that the 30-39-year-olds rated 
their continuous learning skills as higher than the over 50year-olds $(p=.40)$, and clear evidence that they considered their action-based learning skills better than the over 50-yearolds $(p=.001)$. The Kruskal-Wallis test also showed a statistically nearly significant difference $(p=.012)$ between the under 30-year-olds and over 50-year-olds for action-based learning. Finally, it was found that the youngest age group felt more confident than the oldest age group about having skills required in the further development of their practical competence $(p=.020)$.

\subsection{Self-rated interaction competence}

In the last results section, the focus is on interaction skills. Interaction competence is a natural part of all client work and has in that sense already been included in much, if not all, of the earlier results presented above. When specifically asked about their interaction skills, the respondents produced the highest ratings: fairly good (47\%) and very good (45\%). Equally high ratings were obtained for empathy (fairly good $51 \%$; very good $44 \%$ ). The results were still very strong for team and group work (fairly good 57\%; very good $37 \%$ ). The respondents were slightly less confident about their capacity to identify factors that influenced group dynamics. Their ratings were fairly good $49 \%$; very good $26 \%$, and neither good nor poor $22 \%(n=24)$.

\section{Discussion}

In this study, the great majority of the 107 respondents in SMEs were satisfied with the simulation coaching planned for them and found it useful from the perspective of practice. Although one-fifth of the participants found that they had not had many possibilities to suggest learning contents, nearly $90 \%$ of all respondents still found that their learning needs had been fairly well or very well attended to, and over $80 \%$ said that the simulation coaching had promoted their professional competence.

From the perspective of the enterprises, it is especially important that over $80 \%$ of the respondents found that the contents learned were useful and adaptable. The fact that the participants rated their continuous learning and creative problemsolving skills very high can also be considered encouraging for the development of both individuals and organizations. In general, the study showed that the respondents had solid selfrated theoretical, practical and, especially, interaction skills, but had plenty of learning needs as regards information and communication technology. This may be partly explained by the fact that electronic documentation systems are not yet present in all small and medium-sized enterprises, and information technology in general may not be used much.

Some differences related to age and occupation were detected in the analysis. None of them were unexpected; it seems natural that nurses should have more knowledge of physical function and acute illness than representatives of other occupations, for example social care professionals. It is also not surprising that younger age groups may be more competent to use the latest information and communication technology. Up until now, the hesitation in using new technology has been explained by the high age of Finnish health and social welfare professionals. ${ }^{[36]}$

Whether age-related or not, the challenges in remote counseling, use of digital tools and robotics need to be addressed. The national policy is to increase the use of assistive technology, especially to serve the growing older population. Successful use of technology can support clients' self-care, self-determination, and autonomy, but it can also be useful to family caregivers and offer professionals a wider range of tools for their work. ${ }^{[37]}$

\section{Conclusions}

The results of this study indicate a need to provide continuing education on information and communication technology for social and healthcare staff in SMEs.

\section{CONFLiCTS OF INTEREST DisClosure}

The authors declare they have no conflicts of interest.

\section{REFERENCES}

[1] Collin K. Experience and shared practice. Design engineers' learning at work [dissertation]. Jyväskylä (Finland): Jyväskylä Studies in Education, Psychology and Social Research 261, University Printing House; 2005

[2] Salminen-Tuomaala M, Kangasluoma E, Kurunsaari MT, et al. Social and healthcare staff's self-reported Simulation learning needs in small and middle-sized enterprises. Clin Nurs Stud. 2018; 6(3): 1-10. https://doi.org/10.5430/cns . v6n3p46

[3] Billett S. Workplace participatory practices. Conceptualising work- places as learning environments. J Workplace Learn. 2004; 16(6): 312-24. https://doi.org/10.1108/13665620410550295

[4] Argyris C, Schön DA. Organizational learning 1l: theory, method and practice. Addison-Wesley; 1996.

[5] Engeström Y. Expansive learning at work: toward an activity theoretical reconceptualization. J Educ Work. 2001; 14(1): 133-56. https ://doi.org/10.1080/13639080020028747

[6] Collin K, Paloniemi S. Supporting experience sharing as participatory workplace practice. In S. Billett, C. Harteis, A. Eteläpelto (Eds.) Emerging perspectives on learning through work. Sense Publishers; 
2008. 167-81 p.

[7] Grimshaw JM, Shirran L, Thomas R, et al. Changing provider behavior: an overview of systematic reviews of interventions. Med Care. 2001; 39(2): 112-45. https://doi.org/10.1097/00005650-2 00108002-00002

[8] Polo F, Cervai S, Kantola J. Training culture: a new conceptualization to capture values and meanings of training in organizations. J Workplace Lear. 2018; 30(3):162-73. Available from: https://doi.org/10.1108/JWL-01-2018-0024

[9] Jacobs BL. Teaching and learning negotiation in a simulated environment. Widerer L J. 2008; 18: 91-112.

[10] Salminen-Tuomaala M, Paavola K, Paussu P. Health and social care leaders' self-rated competence and learning needs in small and medium-sized enterprises. Clin Nurs Stud. 2019; 7(2): 62-70. https://doi.org/10.5430/cns.v7n2p62

[11] Hansen J, Bratt M. Competence acquisition using simulated learning experiences: a concept analysis. Nurs Educ Perspect. 2015; 36(2): 102-7. PMid: 29194134. https://doi .org/10.5480/13-1198

[12] Kellomäki M. Simulaatio hoitotieteen asiantuntijan vuorovaikutuskoulutuksessa - opiskelijoiden kokemuksia. [Simulation in nursing science's professional communication education - students' experiences] [master thesis]. Joensuu (Finland): University of Eastern Finland; 2013. 62 p. Available from: http://epublications.uef.fi/pub/urn_nbn_fi_uef-201 30530/urn_nbn_fi_uef-20130530.pdf

[13] Buxton M, Phillippi JC, Collins MR. Simulation: a new approach to teaching ethics. J Midwifery Womens Health. 2014; 60(1): 70-4. PMid: 25141791. https ://doi.org/10.1111/jmwh.12185

[14] Westli HK, Johnsen BH, Eid J, et al. Teamwork skills, shared mental models, and performance in simulated trauma teams: an independent group design. Scand J Trauma Resusc Emerg Med. 2010; 18(47): 18. PMid: 20807420. https ://doi.org/10.1186/1757-7241-1 8-47

[15] Razavi D, Delvaux N, Marchal S, et al. Testing health care professionals' communication skills: the usefulness of highly emotional standardized role-playing sessions with simulators. Psychooncology. 2000; 9: 293-302. https://doi.org/10.1002/1099-1611 (20 0007/08) $9: 4<293$ : : AID-PON461>3.0.CO;2-J

[16] Heaven C, Clegg J, Maguire P. Transfer of communication skills training from workshop to workplace: the impact of clinical supervision. Patient Educ Couns. 2006; 60: 313-25. PMid: 16242900. https://doi.org/10.1016/j.pec.2005.08.008

[17] Zavertnik J, Huff T, Murno C. Innovative approach to teaching communication skills to nursing students. J Nurs Educ. 2010; 49(2): 65-71. PMid: 19810670. https://doi.org/10.3928/01484834 $-20090918-06$

[18] Gabrielsen AK, Wallander Karlsen MM, Falch AL, et al. Communication training course with simulation. Sykepleien Forskning 2016; 11(2): 184-192. https://doi.org/10.4220/Sykepleienf . 20 16.57832

[19] Laschinger S, Medves J, Pulling C, et al. Effectiveness of simulation on health profession students' knowledge, skills, confidence and satisfaction. Int J Evid Based Healthc. 2008; 6(3): 278-302. PMid: 21631826. https://doi.org/10.1111/j.1744-1609.2008.0 $0108 . \mathrm{x}$

[20] European Commission. Alueellisen ennakoinnin käytännön opas. Suomi. [Practical guide to regional foresightin Finland]. 2003. Available from: http://bookshop.europa.eu/fi/alueellisen-e nnakoinnin-kaeytaennoen-opas-suomi-pbKIND20478/

[21] Kukkonen T, Sihvo P, Helminen J, et al. Kokemuksia tulevaisuuden osaamistarpeiden luotaamisesta. Sosiaali-, terveys-, liikunta- ja kauneudenhoitoalojen erikoistumiskoulutustarpeiden kartoittaminen.
[Experiences of gauging future learning needs. Needs for education in social, health, physical education and beauty care]. Joensuu (Finland): Karelia University of Applied Sciences; 2016 Reports 39.

[22] Ministry of Education in Finland. Selvitys koulutus- ja osaamistarpeiden kehittymisestä sekä ennakoinnin tilasta ja kehittämistarpeista. [Development of educational and learning needs, foresight and development needs]. 2008; 5. Yliopistopaino. Available from: http://www.minedu.fi/export/sites/default /OPM/Julkaisut/2008/liitteet/tr05.pdf?lang=fi

[23] Ministry of Social Affairs and Health in Finland. Johtamisella vaikuttavuutta ja vetovoimaa hoitotyöhön. Toimintaohjelma 2009-2011. [Increasing the effectiveness and attraction of nursing care by means of management: an action plan for the years 2009-2011]. Helsinki (Finland): Yliopistopaino; 2009.18 p.

[24] Laine M. Hoitajana huomennakin. Hoitajien työpaikkaan ja ammattiin sitoutuminen. [Organizational and professinal commitment of nurses]. [dissertation]. [Turku, Finland]: University of Turku Publications C; 2005. $191 \mathrm{p}$

[25] Ministry of Education and Culture in Finland. Selvitys koulutusja osaamistarpeiden kehittymisestä sekä ennakoinnin tilasta ja kehittämistarpeista 2010. [Development of educational and learning needs, foresight and development needs in 2010] Working Work Memoranda and Studies. 2011; 11. Available from: http://www.oph.fi/download/132033_OKM_selvity s_koulutus_ja_osaamistarpeiden_tilasta_2010

[26] Ministry of Education and Culture in Finland. Tutkintoon johtavan koulutuksen kehittäminen tukemaan sosiaali- ja terveyspalvelujen uudistamista. [Development of studies leading to a qualification in support of the health and social services reform). Helsinki (Finland): Publications of the Ministry of Education and Culture. 2019; 24.

[27] Perälä S, Mäkelä K, Salmenaho A, et al. Technology for elderly with memory impairment and wandering risk. E-Health Telecommunication systems and Network. 2013; 2(1): 13-22. https ://doi .org/ 10.4236 /etsn.2013.21003

[28] Salminen-Tuomaala M, Paavola K, Paussu P. Health and social care leaders' self-rated competence and learning needs in small and medium-sized enterprises. Clin Nurs Stud. 2019; 7(2): 62-70. https://doi.org/10.5430/cns.v7n2p62

[29] Polit DF, Beck CT. Nursing research: generating and assessing evidence for nursing practice. 9th ed, Philadelphia: Lippincott Williams \& Wilkins; 2012

[30] TENK Finnish Advisory Board. Research integrity, responsible conduct of research and procedures for handling allegations of misconduct in Finland. 2012 (In Finnish, Swedish and English). Available from: http://www.tenk.fi/files/HTK_ohje_2013.pdf

[31] Grove SK, Burns N, Gray J. The practice of nursing research appraisal, synthesis and generation of evidence. 7th ed. St Louis (MO): Saunders, Elsevier; 2013.

[32] Burns N, Grove SK. The practice of nursing research: appraisal, synthesis and generation of evidence. 7 edition. Philadelphia. W.B. Saunders Company; 2009.

[33] Kankkunen P, Vehviläinen-Julkunen K. Tutkimus hoitotieteessä. [Research in nursing science]. Sanoma Pro Oy; 2018.

[34] Heikkilä T. Tilastollinen tutkimus. [Statistical research]. Edita Publishing Oy; 2014.

[35] Hamilton MB. Online survey response rates and times: background and guidance for industry. J Travel Res. 2003; 49(1): 121-35.

[36] Suhonen L, Ahtiainen M, Siikanen T. Hyvinvointiteknologia sosiaalija terveysalan koulutuksessa. [Welfare technology in social and healthcare education] in L. Suhonen \& T. Siikanen (Eds.) Hyvinvointiteknologia sosiaali- ja terveysalalla - hyöty vai haitta? [Welfare 
technology in social and health care-a benefit or a disadvantage?] Tampere: Tampereen yliopistopaino Oy; 2006. 21-31 p.

[37] Ministry of Social Affairs and Health in Finland. Laatusuositus hyvän ikääntymisen turvaamiseksi ja palvelujen parantamiseksi 2017-2019.
[Quality recommendation to guarantee a good quality of life and improved services for older persons 2017-19. Helsinki (Finland): Publications of the Ministry of Social Affairs and Health in Finland; 2017. $6 \mathrm{p}$. 